\title{
(TRANS)AÇÕES ENTRE DEVIRES E DEVERES: ATENDIMENTO PSICOSSOCIAL AMPLIADO COM POPULAÇÃO LGBT EM CONTEXTO DE PRIVAÇÃO DE LIBERDADE
}

\author{
Márcio Alessandro Neman do Nascimento ${ }^{1}$ \\ Jefferson Adriã Reis ${ }^{2}$ \\ Eloize Marianny Bonfim da $\operatorname{Silva}^{3}$
}

Resumo: O programa de ações extensionistas (Trans)ações entre devires e deveres: atendimento psicossocial ampliado com população LGBT em contexto de privação de liberdade está alocado no Laboratório Esquizoanalista de Produção de Subjetividade e(m) Interseccionalidades (LEPSI). Por meio do tripé teoria-prática-supervisão, este programa oferece atendimento psicossocial ampliado a pessoas LGBT em contexto de privação de liberdade em uma unidade prisional localizada na região sul do estado de Mato Grosso. Tais ações visam minimizar sofrimentos psicossociais provenientes de homo-lesbo-bitransfobias, além de possibilitar, por meio de ações socioeducativas, a potencialização da vida, de modo a produzirem transformações na vida institucional e egressa dos reeducandos. Apoiamo-nos no posicionamento teórico-metodológico esquizoanalista (método cartográfico) e desenvolvemos ações convergentes e complementares, tais como: atendimento individual; construção de horta comunitária; projeto clube de leitura e remição; projeto de autogestão da ala; e oficinas socioeducativas e rodas de conversa sobre vivência LGBT, Direitos Humanos e Cidadania, empregabilidade, saúde, vida institucional e egressa que emergem em problematizações relacionadas às vulnerabilidades pessoais, sociais, programáticas e institucionais. Percebemos, com tudo isso, que o programa contribui para o fortalecimento de um espaço pensado para que as pessoas LGBT em situação de aprisionamento possam vivenciar a vida institucional carcerária e a ressocialização com os efeitos da homo-lesbo-bi-transfobia reduzidos.

Palavras-chave: Aprisionamento; População LGBT; Método Cartográfico.

\footnotetext{
${ }^{1}$ Psicólogo. Professor Adjunto do curso de Psicologia da Universidade Federal de Rondonópolis (UFR). Coordenador do Laboratório Esquizoanalista de Produção de Subjetividade e(m) Interseccionalidades (LEPSI). Coordenador do programa de ações extensionistas (Trans)ações entre devires e deveres: atendimento psicossocial ampliado com população LGBT em contexto de privação de liberdade. E-mail: marcioneman@gmail.com

${ }^{2}$ Formado pelo curso de Letras da Universidade Federal de Mato Grosso - (UFMT)/Câmpus Rondonópolis. Graduando do curso de Psicologia da UFR. Integrante do LEPSI. E-mail: jeffersonadriareis@ gmail.com

${ }^{3}$ Graduanda do curso de Psicologia da UFR. Integrante do LEPSI. E-mail: eloizemb @ gmail.com Vol. 01, N. 04, Out. - Dez., 2018 -www.revistas.unilab.edu.br/index.php/rebeh
} 


\section{Cena 1: Além do horizonte, existe um lugar...}

O prédio se revela, ao longe, com suas torres e seus altos muros. $\mathrm{O}$ avistamos um tanto antes de nos aproximarmos. Em alguns minutos estaremos na Penitenciária Regional de Rondonópolis Major PM Eldo Sá Correa "Mata Grande”. Recortada contra o céu, ora nublado ora de um azul profundo, a construção se torna cada vez mais nítida e real. Estamos diante de muitas vidas, muitas histórias, muitas existências que agora se encontram ali, naquele espaço de privação de liberdade. Conhecemos os procedimentos, o som das trancas, os uniformes, as formalidades e cumprimentos. Estamos preparados para desenvolver uma oficina na Ala LGBT Aquarel@s.

Como estagiários e extensionistas, também somos afetados pela vida institucionalizada. Afetados no sentido de construirmos afetos e de não estarmos imunes aos procedimentos de segurança e ao modo de vida dentro dos muros. O sistema prisional, como um todo, apresenta uma gama de condições facilitadoras para o adoecimento das pessoas ligadas a ele, sejam aprisionados, servidores ou demais profissionais que atuam nessa área. A privação de liberdade é um fator que, somando-se e atravessando outros elementos heterogêneos de subjetivação, produz modos de existir e propõe outras configurações nas paisagens psicossociais.

Em um país com alto índice de violências ligadas à discriminação e crimes de ódio, como o machismo, a misoginia, a homo-lesbo-bi-transfobia, e que recebe grande influência da moral cristã, as minorias sociais encontram-se ainda mais vulneráveis no cárcere, uma vez que as dizibilidades e visibilidades sobre os modos de olhar, pensar, agir são cerceados pelas biopolíticas e pelas estratégias do biopoder que, aos poucos, produzem corpos docilizados, disciplinados e controlados por diversos agenciamentos discursivos que se mesclam e se (con)fundem entre pensamentos macropolíticos e práticas sociais institucionalizadas da micropolítica prisional (FOUCAULT, 1987, 2003).

Em nossa prática, percebemos como esses discursos influenciam as atuações dentro das unidades de segurança, os papéis que são adotados e desenvolvidos, a rotina e a forma como as relações são estabelecidas. Como pertencentes ao campo dos estudos da Psicologia, nos questionamos: O que pode a Psicologia em relação ao enfrentamento da homo-lesbo-bi-transfobia nos sistemas prisionais, visto que há um extenso trajeto para que os Direitos Humanos fundamentais sejam respeitados nesse contexto?

Vol. 01, N. 04, Out. - Dez., 2018 - www.revistas.unilab.edu.br/index.php/rebeh 
A população LGBT encarcerada, que apresenta processos de estigmatização e vulnerabilidades provenientes da vida extramuros, não está livre das homo-lesbo-bitransfobias, da "heteronormatividade compulsória" (RICH, 1980) ou da "heterossexualidade obrigatória" (RUBIN, 2003), que, em um sistema sexo/gênero binário, compreende a heterossexualidade como uma condição "natural"; essa visão do binário sexual homem/mulher, macho/fêmea, masculino/feminino é mantida pela transversalidade social que faz com que funcionários e aprisionados reiterem e propaguem pela organização institucional que toda expressão de sexualidade e identidade de gênero que não parta da matriz heterossexual seja considerada desviante, anormal, patológica (NASCIMENTO, 2010).

Lésbicas, gays, bissexuais, transexuais e travestis estão sujeitos a violências que vão desde o desrespeito ao uso do nome social, no caso de transexuais e travestis, ao estupro e à tortura. No sistema prisional, a pessoa LGBT não é punida apenas de acordo com a infração que cometeu, mas também recebe uma carga extra de sofrimento por não se adequar às normas e aos dogmas de uma sociedade patologizante, estigmatizante, opressora, homo-lesbo-bi-transfóbica, racista, misógina, classista e fortemente baseada em um modo binário de produzir moralidades advindas do cristianismo (DAVIS, 2003, 2016; BAYER \& RANGEL, 2016).

De acordo com Gershenson et al. (2017), podemos observar que as relações de opressão de cunho transfóbico nas unidades de segurança são transpassadas pelo machismo, sexismo, racismo e classismo. Travestis e mulheres transexuais são na maioria das vezes aprisionadas em instituições destinadas a homens, onde ficam obrigadas a realizar tarefas socialmente atribuídas ao gênero feminino, como cuidar da limpeza das celas, e sofrem violências machistas de homens apreendidos, que se colocam em posição superior em relação a elas. Os autores ainda apontam que a prática de rituais de religiões de matriz africana fica impossibilitada e que as demandas de travestis e mulheres transexuais são recebidas pelos agentes penitenciários como sendo pouco importantes.

Esses crimes contra essa população são justificados pela sociedade punitiva e opressora como sendo parte da punição sentenciada. Indagamos: quem defende a população LGBT encarcerada? É comum o discurso de que não é necessário que nos preocupemos com os direitos das pessoas aprisionadas, porque estas são criminosas, inúteis para a sociedade e que merecem sofrer pelo mal que causaram. Integra-se a esse

Vol. 01, N. 04, Out. - Dez., 2018 - www.revistas.unilab.edu.br/index.php/rebeh 
discurso a fala de que não se deve pensar políticas públicas específicas para a população LGBT em situação de privação de liberdade, como se tais políticas fossem benefícios e não ações que possibilitem um mínimo de dignidade e condições de ressocialização a essas pessoas.

De acordo com a Política Nacional de Saúde Integral de Lésbicas, Gays, Bissexuais, Travestis e Transexuais (BRASIL, 2013), as homofobias são disparadores sociais de adoecimentos, sejam eles do campo da saúde mental, como depressão e ansiedade, como também aqueles ligadas às vulnerabilidades surgidas pela vivência da sexualidade de forma clandestina, resultado dos processos de estigmatização, marginalização, segregação e discriminação.

Com essa realidade em vista, fazemos do programa de extensão (Trans)ações entre devires e deveres: atendimento psicossocial ampliado com população LGBT em contexto de privação de liberdade um modo de problematizar a homo-lesbo-bi-transfobia e outras discriminações em unidades prisionais. O programa, que está alocado no Laboratório Esquizoanalista de Produção de Subjetividades e(m) Interseccionalidades (LEPSI) realiza ações de atendimento à população da ala LGBT Aquarel@s da Penitenciária Regional de Rondonópolis Major PM Eldo Sá Correa "Mata Grande", que atende toda a região sul de Mato Grosso. Essas ações ancoram-se na teoria, na prática e na supervisão e são realizadas por discentes do curso de Psicologia da Universidade Federal de Rondonópolis.

Nosso objetivo é atuar em parceria com a unidade prisional para o estabelecimento e manutenção das ações que ocorrem na Ala LGBT Aquarel@s, que surgiu a partir de um convite feito por um servidor LGBT responsável pela ala, também discente do curso de Psicologia. A criação da ala LGBT coincidiu com a Instrução Normativa n. ${ }^{\circ}$ 001/2017/GAB-SEJUDH, publicada no Diário Oficial do Estado de Mato Grosso no dia 30 de novembro de 2017. Tal normativa estabelece parâmetros de acolhimento e atendimento a pessoas LGBT privadas de liberdade no Sistema Penitenciário de Mato Grosso. Assim, a unidade prisional, juntamente com o LEPSI, já desenvolvia a ala LGBT antes da publicação da normativa e hoje o espaço se encontra em funcionamento e com as vagas ocupadas.

\section{Cena 2: "Quid pro quo" - por uma metodologia do pensamento nômade}

Vol. 01, N. 04, Out. - Dez., 2018 - www.revistas.unilab.edu.br/index.php/rebeh 
Todas as práticas realizadas pelos participantes do projeto são ações interventivas que visam minimizar as homo-lesbo-bi-transfobias institucionais, visto que essa população encontra-se em contexto de privação de liberdade, situação facilitadora para que os processos de estigmatização das sexualidades dissidentes ou singulares aumentem as condições de vulnerabilidades sociais, incluindo extermínio, uma vez que estando confinados, se torna impossível a defesa, esquiva ou fuga.

Figura 1 - Roda de conversa sobre vivência LGBT

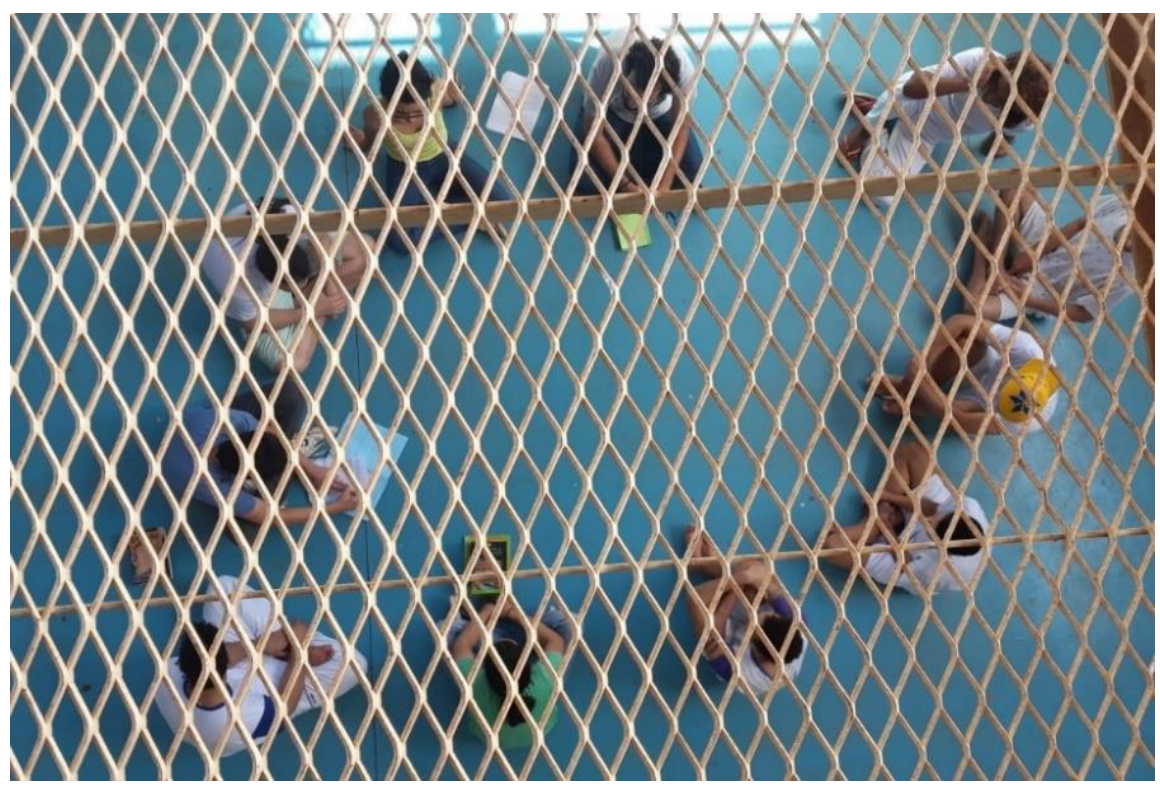

Fonte: Acervo do Projeto

As ações e projetos realizados com os reeducandos dividem-se em oficinas socioeducativas e rodas de conversa sobre vivência LGBT, Direitos Humanos e Cidadania, empregabilidade, saúde, vida institucional e egressa; construção de horta comunitária; projeto clube de leitura e remição, que oferece acesso a um acervo de livros criado e mantido pelos estagiários e desenvolve oficinas de leitura, oficinas de escrita e acompanhamento na produção das resenhas; e atendimento individual, que oferece apoio psicológico, escuta sensível e acompanha o desenvolvimento dos reeducandos. Para além do trabalho com o público destinatário, também realizamos a participação e representação política junto à Comissão LGBT da Secretaria de Justiça e Direitos Humanos do Estado de Mato Grosso (SEJUDH); discussões de pautas com a direção da unidade prisional, com o setor pedagógico e, de modo randômico e rizomático, com os demais funcionários. 
O método cartográfico baseado no posicionamento teórico-metodológico esquizoanalista criado por Gilles Deleuze e Félix Guattari é a base das ações e das supervisões. Os estagiários participam de um grupo de estudos que tem por objetivo reforçar o aporte epistemológico/filosófico, tanto em relação ao entendimento das políticas públicas quanto ao posicionamento esquizoanalista e à produção de subjetividades e $(\mathrm{m})$ interseccionalidades. A esquizoanálise analisa a composição macro e micropolítico dos sujeitos, as existências e os desejos a partir de elementos heterogêneos espalhados pelo campo social e que, por assim ser, são atravessadores de produção de subjetividades normatizadoras e/ou singulares/nômades que se interseccionam em um acontecimento rizomático e que se apresentam, ora em zonas rígidas, fixas e de limites, ora em momentos de fuga, criatividade e produção de mundos possíveis. A esquizoanálise (método cartográfico) requer um posicionamento político, ativo e transformador e propõe que a produção de vida afirmativa e potente aconteça a partir da diferença, das existências singulares, da resistência, da criatividade e assim construir estilos de vida e mundos possíveis (NASCIMENTO, 2015). Em outras palavras:

[...] o cartógrafo sabe que é sempre em nome da vida, e de sua defesa, que se inventam estratégias, por mais estapafúrdias. Ele nunca esquece que há um limite do quanto se suporta, a cada momento, a intimidade com o finito ilimitado, base de seu critério: um limite de tolerância para a desorientação e reorientação dos afetos, um "limiar de desterritorialização" (ROLNIK, 1989, p. 70).

Rolnik (1989), ao problematizar a ética esquizoanalista em defesa da vida e em seu compromisso de (re)inventar constantemente as estratégias de resistência e modos possíveis de construir vidas possíveis, leva-nos a entender que o posicionamento político na prática cartográfica nos conecta com aquelas vidas negligenciadas pela falência das instituições (trans)contemporâneas e propõe um modo implicado de fazer psicologia no contexto prisional.

Com nosso programa de ações extensionistas, reafirmamos o compromisso com o rompimento das despotencializações da produção de vida que ocorre referente às pessoas em situação de aprisionamento. Para tanto, é necessário que haja um trabalho em conjunto entre agentes penitenciários, profissionais da educação, profissionais da saúde, servidores administrativos, estagiários e reeducandos para que se torne possível vislumbrar caminhos para a criação de estratégias para uma possível reinserção dessa população específica à

Vol. 01, N. 04, Out. - Dez., 2018 -www.revistas.unilab.edu.br/index.php/rebeh 
sociedade. Ao se problematizar os efeitos da homo-lesbo-bi-transfobia e combater as discriminações no sistema prisional, problematizamos também os marcadores sociais que realizam intersecção com sexualidade/gênero, tais como: classe social e econômica; raça/etnia; geração; nível de instrução escolar; oriundos de regiões e culturas ditas periféricas, entre outros.

As condições criadas pelos próprios integrantes da ala Aquarel@s (nome escolhido por eles) são: a não violência; a horizontalidade; a participação nas oficinas e ações propostas pelo programa; o cuidado com a saúde, o que inclui o acompanhamento realizado pelos profissionais de saúde da instituição; a divisão de tarefas para a manutenção da higiene da ala; a ida à escola para aqueles que frequentam o Ensino Fundamental ou Médio; e a profissionalização.

\section{Cena 2.1: Entre o Teatro do Oprimido e o Esquizodrama - representação do cotidiano e do exagero}

Uma das práticas que adotamos nas oficinas de vivência é o Teatro do Oprimido, de Augusto Boal (1991, 2007), que, partindo de uma perspectiva emancipatória e abolicionista carcerária, questiona a norma punitivista/sancionatória e investe na problematização da proposta socioeducativa. Perguntamos: Quais são os limites, a legitimidade e incidência no cárcere? E sendo a penitenciária uma tecnologia social de confinamento, o que mais ela produz? Em seus processos instituídos, quais corpos serão disciplinarizados e docilizados? Para que e para quem serve o assujeitamento de apenados? O que pode os Direitos Humanos frente ao aprisionamento de pessoas LGBT?

Com essas problematizações, não almejamos respostas rápidas e fechadas. Nas oficinas de dramatização, a "comédia e a "tragédia" realizadas em cenas cotidianas e “absurdas" possibilitam a expressão de sensações, sentimentos, memórias, além de produzir uma experiência compartilhada coletivamente com pessoas que passaram/passam por práticas sociais em suas trajetórias de vidas marginalizadas.

Ao produzirmos coletivamente com os reeducandos, surgem cenas que aconteceram em suas vidas anteriores ao encarceramento, cenas vividas no tocante às regras institucionais e nas relações com funcionários, cenas sobre o convívio e relacionamento sócio-afetivo-sexual na ala. Os processos criativos e absurdos de

Vol. 01, N. 04, Out. - Dez., 2018 -www.revistas.unilab.edu.br/index.php/rebeh 
elaboração ficcional nos possibilitam a eclosão de opiniões complementares ou controversas, que, por sua vez, tornam-se campo fértil para o diálogo e produção de fala.

Em uma ocasião, problematizamos um período em que os reeducandos da ala (re)produziam práticas agressivas uns em relação aos outros (principalmente contra integrantes mais fracos). Realizamos cenas: 1) somente com equipe do programa; 2) somente com os integrantes da ala e; subsequentemente, 3) cena em que mesclamos participantes da ala e da equipe. Reconstruímos cenas de práticas violentas que ocorreram na ala e foram relatadas por alguns, no entanto, em outro contexto social (extramuros). Em uma das cenas elaboradas, uma pessoa com mais força física ou em uma posição privilegiada agredia injustamente uma pessoa mais fraca e que estava em sofrimento psíquico. Nas discussões subjacentes, ecoavam verbalizações, inclusive dos agressores: "Nossa, como as pessoas podem ser injustas? Será que as pessoas não têm dó? Um cara desses tem que apanhar por bater em um mais fraco" (sic). Um outro reeducando relata: “A gente vendo assim [a cena], a gente entende que por viver tantas violências, a gente repassa a agressão e na verdade não era assim que a gente deveria fazer. Se eu não quero ou nunca gostei que fizessem comigo, porque eu faço isso com os outros? Por quê? Vou ficar pensando nesse negócio aí. Até queria pedir desculpa depois...” (sic).

Nesse contexto, ao propormos a horizontalidade, procuramos romper com a cultura "cadeeira" de hierarquização e relações de poder. Para isso, nos alinhamos com a perspectiva de aprendizagem de adultos de Paulo Freire (2011), que promove a horizontalização de saberes em um processo interminável e polifônico de aprenderensinar, como par indissociável na busca por (res)significação das próprias ações e das relações interpessoais. Nossa finalidade é que a construção de saber-poder se localize tanto nos reeducandos quanto nos estagiários, para que possamos promover processos emancipatórios de modos de subjetivação e realidade.

\section{Cena 2.2: Clube de Leitura e Remição... quem conta um conto, aumenta um... ops, diminui um dia na pena}

Ao afirmar que: "Yo prefiero ficcionalizar mis teorías, teorizar mis ficciones y practicar la filosofía como una forma de creatividad conceptual" a filósofa Rosi Braidotti (2000, p. 79) recorre à crítica e à necessidade de transposição da produção de conhecimento que mantem verticalizado os saberes ditos reais em detrimento dos Vol. 01, N. 04, Out. - Dez., 2018 · www.revistas.unilab.edu.br/index.php/rebeh 
ficcionais. Nessa problematização, a autora sugere deliberadamente que possamos interseccionar e mesclar o dito real/ficcional e científico/artístico de modo a construir processos de subjetivação criativa e singular e assim, produzir sujeitos nômades, ou seja, pessoas que saem de uma rigidez de pensamento e produzem plasticidade psíquica que torne os pensamentos passíveis de mobilização e transposição.

Nessa perspectiva, as oficinas do Clube de Leitura e Remição são baseadas no princípio de que a leitura e a escrita são potencializadores importantes no processo de ressocialização e de (re)descoberta de si. Percebemos que é possível, por meio dos livros, gerar discussões e instigar um posicionamento crítico dos reeducandos sobre suas vidas, tanto como protagonistas de suas próprias existências quanto como conhecedores das forças sócio-histórico-político e culturais que contribuem para que ocupem aquele espaço social restrito.

Ao apresentarmos obras culturais aos reeducandos, temos a finalidade de tornar a vida institucional menos agressiva em relação à produção de subjetividades, principalmente em frente à tendência de apagamento do sujeito nas instituições prisionais. As ações empreendidas oferecem oficinas de escrita, oficinas de leitura, exibição de filmes e rodas de conversa, na perspectiva de possibilitar um ambiente de coletividade onde se possa falar sobre temas diversos. Para conseguir a remição, o reeducando dispõe de um mês para ler o livro e escrever uma resenha, que equivale a quatro dias de remição da pena.

O acervo literário é mantido e organizado pelos estagiários. Hoje, contamos com um total aproximado de 600 livros, a maioria proveniente de doações. Entre as obras, temos títulos que vão desde a literatura clássica, como Os Miseráveis, de Victor Hugo, a best-sellers contemporâneos, como a coleção Harry Potter, de J. K. Rowling. Entre os mais requisitados estão as histórias de amor e as narrativas de mistério. Há um reeducando, em particular, que descobriu o gosto pela leitura de mangás. Em se tratando das leituras realizadas em grupo, preferimos levantar discussões tendo como base trabalhos de autores nacionais, sobretudo aqueles com representatividade LGBT.

Enxergamos o clube de leitura e remição como ferramenta útil ao integrar e interligar as outras ações do programa realizadas com a Ala LGBT Aquarel@s, como as oficinas de vivência e os atendimentos individuais. Os encontros são espaços em que se tornam visíveis as relações estabelecidas pelos reeducandos, tanto entre eles quanto com

Vol. 01, N. 04, Out. - Dez., 2018 - www.revistas.unilab.edu.br/index.php/rebeh 
a instituição, o que colabora com a criação de estratégias educativas, resolução de conflitos e de fortalecimento individual e coletivo. Além disso, as leituras e as discussões modificam a paisagem psicossocial e seus horizontes, promovendo a mudança e levando os reeducandos a construir saberes diversos.

\section{Cena 2.3: "O que ainda não sei, mas sei que preciso saber" - a proposta de capacitação e relacionamento com os servidores}

Integrando as atividades do programa de extensão há ainda a proposta da capacitação dos servidores sobre vivências e direitos das pessoas LGBT. Com essa capacitação, objetivamos reforçar o que é trazido pela Instrução Normativa n. ${ }^{\text {o }}$ 001/2017/GAB-SEJUDH e esclarecer quaisquer dúvidas que possam surgir. Pretendemos, com isso, apoiar os servidores em práticas que não sejam mantenedoras ou resquícios da homo-lesbo-bi-transfobia. Dentro deste planejamento foram realizadas capacitações com os profissionais da educação ligados à Escola Nova Chance, que atuam na unidade prisional. No entanto, é necessário investir para que essas ações sejam sistematizadas para com todos os funcionários dos diversos plantões e setores.

Figura 2 - Parte da equipe no dia da inauguração da Ala Aquarel@ s

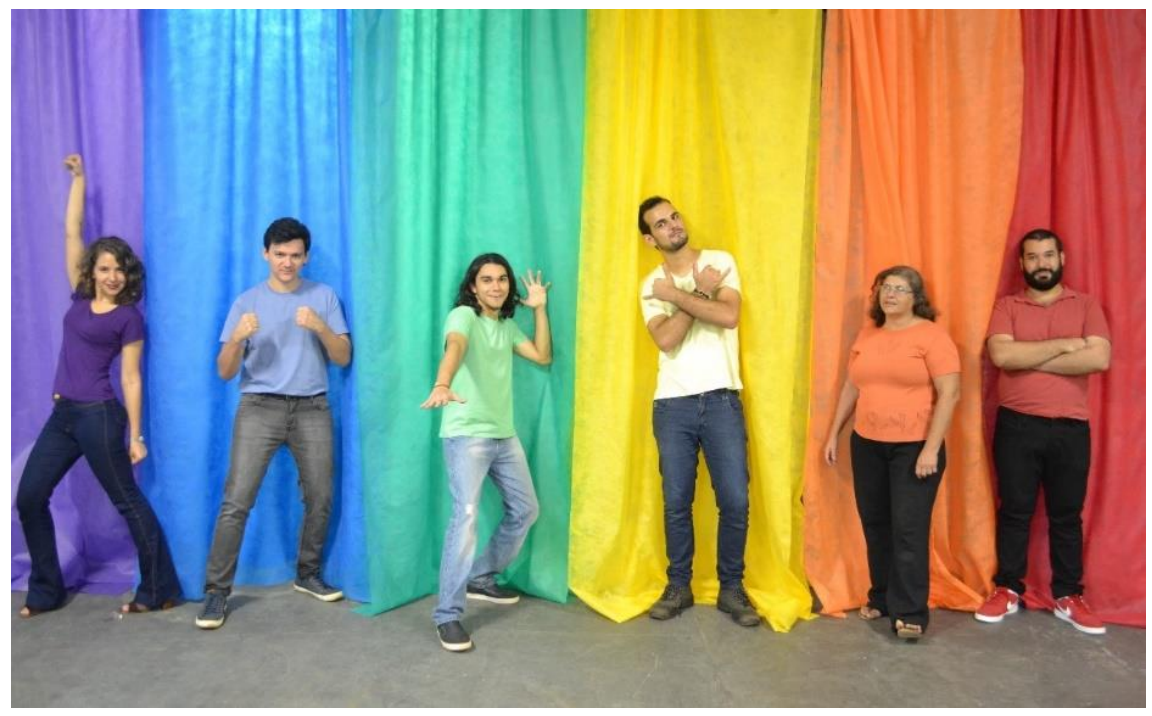

Fonte: Acervo do Projeto

Uma das atividades que visaram a apresentação do projeto junto à comunidade prisional (agentes penitenciários e servidores de diversos setores) foi a inauguração da Ala

Vol. 01, N. 04, Out. - Dez., 2018 - www.revistas.unilab.edu.br/index.php/rebeh 
Aquarel@s, que aconteceu no dia 26 de junho de 2018. Embora as ações do projeto tenham tido início na segunda quinzena de agosto de 2017 , foi nesse momento que a comunidade prisional pode compreender mais efetivamente a proposta a ser cumprida de acordo com a Instrução Normativa n. ${ }^{\circ}$ 001/2017/GAB-SEJUDH. O longo tempo passado entre o início das atividades e a inauguração da ala ocorreu por conta da necessidade de se consolidar o projeto na prática, uma vez que, para a unidade, era uma ação inovadora e que iria modificar a paisagem psicossocial da instituição. A publicização na imprensa, no Estado de Mato Grosso, disparou diversos pensamentos e curiosidades entre os funcionários, de modo que surgiu a emergência da futura capacitação sistematizada.

\section{Cena 2.4: "É atendimento clínico ou apoio psicossocial que fala?" - plano individual de atendimento}

Como modelo organizador de práticas socioeducativas para a transformação da vida institucional e egressa dos reeducandos que compõem a ala Aquarel@s, nos baseamos no Sistema Nacional de Atendimento Socioeducativo - SINASE (BRASIL, 2006). Apesar de o SINASE ser destinado ao acolhimento e atendimento de adolescentes, percebemos que é possível utilizar suas ferramentas para atender e acolher pessoas adultas apreendidas, uma vez que, devido às poucas condições socioeconômicas, aos somativos processos de estigmatização e situações de vulnerabilidades, às políticas públicas e instituições falhas, deficientes ou inexistentes, entre outros, muitos integrantes da ala necessitam de acolhimentos que lhes foram negados. Uma parcela significativa de integrantes da ala está na faixa etária entre 18 a 21 anos, idades incluídas e descritas como na fase da adolescência para alguns teóricos e descritas em documentos e normativas de políticas públicas inclusivas.

O SINASE apresenta o Plano Individual de Atendimento (PIA), que é construído a partir de uma análise polidimensional, abarcando, assim, as áreas jurídica, de saúde, psicológica, social e pedagógica. Desta forma, procura-se pensar as esferas da vida do reeducando em uma trajetória que é decidida e discutida com ele. As evoluções e observações são registradas no PIA de modo a acompanhar o desenvolvimento longitudinal, falhas na proposta institucional, insurgência de novas problematizações e fechamento de questões superadas. Essa ação é realizada em especificidade com as áreas da saúde, pedagógica, entre outras, sendo preservada a condição ética do código Vol. 01, N. 04, Out. - Dez., 2018 - www.revistas.unilab.edu.br/index.php/rebeh 
profissional do psicólogo, no que tange ao apoio psicossocial realizado por estagiários e estagiárias. Embora possam surgir possíveis críticas relacionadas ao processo de institucionalização referente ao PIA enquanto modelo implantado, é importante salientar que o posicionamento teórico-metodológico-político dos atendimentos e, subsequente, das supervisão das ações extensionistas pelo coordenador do programa, é baseado na proposta esquizoanalista, anteriormente mencionada.

Assim sendo, é importante que o reeducando perceba suas potencialidades e dificuldades, em análises contextuais e localizadas, a partir das transversalidades e interseccionalidades, ou seja, a partir das linhas de produção de subjetividade que o compõe enquanto sujeito. É fundamental, ainda, que o reeducando se compreenda como agente modificador da própria vida, no entanto, que também esteja ciente das forças macropolíticas que empobrecem a vida coletiva de grupos ditos minoritários ou em contexto de vulnerabilidades. As atividades e ações do programa fundamentam-se nesse preceito polidimensional e tencionam promover a criticidade dos reeducandos em relação às várias esferas sociais e individuais que os compõem, tanto no campo macropolítico quando da formulação micropolítica do desejo, do pensar, do agir e existir.

O PIA, onde se registra todas as informações relacionadas a essas esferas específicas, funciona como um facilitador para a troca de informações pertinentes a cada reeducando, o que ajuda na elaboração do passo-a-passo e dos temas a serem trabalhados nas ações. Embora grande parte das temáticas sejam problematizadas nas diversas oficinas contínuas e diversificadas, é notória a necessidade de procurar atendimentos individuais para assuntos que trazem desconforto aos reeducandos e os deixam demasiadamente sensíveis nas oficinas, como, por exemplo, a sorologia positiva para o vírus HIV; violências intrafamiliares e/ou sexuais; questões de saúde mental e utilização de medicamentos psicotrópicos; a dificuldade em lidar com a abstinência, entre outros. Devido a ala possuir integrantes sentenciados e não-sentenciados, a rotatividade de reeducandos traz insegurança quanto a se "mostrarem aos outros" sem os conhecê-los. As questões pertinentes aos relacionamentos afetivo-sexuais têm se apresentado como uma das grandes solicitações para serem atendidas individualmente fora do espaço comunitário da ala. De uma forma ou de outra, as problemáticas trazidas para o campo individual acabam por nos instrumentalizar para criar novas oficinas temáticas.

Vol. 01, N. 04, Out. - Dez., 2018 - www.revistas.unilab.edu.br/index.php/rebeh 


\section{Cena “O (in)conclusivo modo de dizer”: el@s ainda estão lá e são muit@s}

O programa de extensão (Trans)ações entre devires e deveres: atendimento psicossocial ampliado com população LGBT em contexto de privação de liberdade procura desenvolver um trabalho que minimize os efeitos da homo-lesbo-bi-transfobia na vida intramuros dos reeducandos que compõem a ala LGBT Aquarel@s, da Penitenciária Regional de Rondonópolis Major Eldo Sá Correa "Mata Grande". Por meio de oficinas socioeducativas e projetos como o clube de leitura e remição e a oficina de vivência, o programa busca instigar nos reeducandos o desejo de crescimento pessoal e um criticismo

em relação ao seus protagonismos como atores sociais, bem como a percepção das forças atuantes no contexto sócio-histórico-político e cultural que os atravessam, os compõe e produzem seus modos de agir e pensar, principalmente no modo em que cada um deles se coloca politicamente na sociedade quanto pessoa LGBT.

Nesse aspecto, o programa tem contribuído para a consolidação de um espaço pensado para que a pessoa LGBT aprisionada na Unidade Prisional vivencie a ressocialização e cumpra as medidas cautelares sem se tornar vítima de violências físicas, morais e psicológicas resultantes das homo-lesbo-bi-transfobias, que tenha sua sexualidade e sua identidade de gênero respeitadas, que tenha acesso a atividades socioeducativas, que se torne consciente dos processos estigmatizantes e das relações de poder operantes na sociedade, que problematize novos modos de existir na comunidade e que tenha a oportunidade de olhar para a própria trajetória de forma crítica.

Nessa perspectiva, o programa de extensão tem avançado na mudança da paisagem psicossocial ao pensar a diversidade sexual, de gênero, afetiva e demais multiplicidades do humano. Essa paisagem psicossocial refere-se tanto ao espaço da ala, vivenciado pelos reeducandos, quanto ao espaço institucional/administrativo, vivenciado por agentes penitenciários e demais servidores. As oficinas e ações produzem (trans)formações a partir de saberes diversos, desenvolvidos com as discussões surgidas nas oficinas de leitura e de vivência e demais atividades propostas. Uma ala LGBT e um programa de extensão destinado a esse público são, por si só, nos dias de hoje, componentes capazes de suscitar muitas modificações na paisagem psicossocial.

\section{Referências}

Vol. 01, N. 04, Out. - Dez., 2018 -www.revistas.unilab.edu.br/index.php/rebeh 
BAYER, Diego Augusto; RANGEL, Caio Mateus Caires. A precariedade do sistema prisional e a responsabilidade do Estado brasileiro face aos crimes de tortura praticados no cárcere à luz dos direitos humanos. Ciências Sociais Aplicadas em Revista - UNIOESTE/MCR, v. 16. nº 30, 2016, p. 95-114.

BRAIDOTTI, Rosi. Sujetos nómades. Buenos Aires: Paidós, 2000.

BRASIL. Ministério da Saúde (MS). Política Nacional de Saúde Integral de Lésbicas, Gays, Bissexuais, Travestis e Transexuais - LGBT. Brasília: MS, 2013.

. Secretaria de Estado de Justiça e Direitos Humanos. Instrução normativa $n^{\circ}$ 001/2017/GAB-SEJUDH. Estabelece parâmetros de acolhimento e atendimento à Lésbicas, Gays, Bissexuais, Travestis e Transexuais - LGBT, privados de liberdade no Sistema Penitenciário do Estado de Mato Grosso e dá outras providências. Diário Oficial do Estado de Mato Grosso, Cuiabá, MT, 30 nov. 2017. p. 77-78.

. Secretaria Especial dos Direitos Humanos. Sistema Nacional de Atendimento Socioeducativo - SINASE. Brasília: CONANDA, 2006.

BOAL, Augusto. Teatro do oprimido e outras poéticas políticas. 6. ed. Rio de Janeiro: Civilização Brasileira, 1991.

2007.

Jogos para atores e não-atores. 10. ed. Rio de Janeiro: Civilização Brasileira,

DAVIS, Angela Yvonne. Are Prisons Obsolete? New York: Seven Stories Press, 2003.

. Mulheres, raça e classe. São Paulo: Boitempo, 2016 [1981].

FOUCAULT, Michel. Vigiar e punir: nascimento da prisão. Trad. Raquel Ramalhete. 19. ed. Petrópolis: Vozes, 1987.

. Prisões e revoltas nas prisões. In: Ditos e escritos IV: estratégia, poder-saber. Organização e seleção de textos de Manuel Barros da Motta. Trad. Vera Lucia Avellar Ribeiro. Rio de Janeiro: Forense Universitária, 2003, p. 61-68.

FREIRE, Paulo. Pedagogia do oprimido. 50. ed. São Paulo: Paz e Terra, 2011.

GERSHENSON, Beatriz et al. Juventudes encerradas: extermínio e aprisionamentos segundo opressões de raça, classe e gênero. Argum., Vitória, v. 9, n. 1, p. 119-133, jan./abr. 2017. Disponível em:

<http://www.publicacoes.ufes.br/argumentum/article/viewFile/13724/10935>.

NASCIMENTO, Márcio Alessandro Neman do. Ladrão Sim, bicha nunca!: práticas homofóbicas entre adolescentes masculinos em uma instituição socioeducativa brasileira. Educação, Sociedade \& Culturas, nº 31, 2010, p. 67-81.

Vol. 01, N. 04, Out. - Dez., 2018 - www.revistas.unilab.edu.br/index.php/rebeh 
Corpos (con)sentidos: cartografando processos de subjetivação de produto(re)s de corporalidades singulares. 2015. 265f. Tese (Doutorado em Psicologia). - Faculdade de Ciências e Letras, Universidade Estadual Paulista, Assis, 2015.

RICH, Adrienne. Compulsory Heterosexuality and Lesbian Existence. Signs. v. 5, n. 4, Women: Sex and Sexuality, 1980, p. 631-660.

ROLNIK, Suely. Cartografia Sentimental: transformações contemporâneas do desejo. São Paulo: Estação Liberdade, 1989.

RUBIN, Gayle. El tráfico de mujeres: notas sobre la economía política del sexo. Trad. Stella Mastrangelo. In: LAMAS, Martha (Comp.). El gênero: la construcción cultural de la diferencia sexual. 3. ed. México: Miguel Ángel Porrúa: Programa Universitario de Estudios de Género - UNAM, 2003. p. 35-96.

\title{
(TRANS)ACTIONS BETWEEN BECOMING AND DUTIES: EXTENDED PSYCHOSOCIAL CARE WITH FREEDOM DEPRIVED LGBT POPULATION
}

\begin{abstract}
The program of extensionist actions "(Trans)actios between becoming and duties: extended psychosocial care with freedom deprived LGBT population" is allocated in the Schizoanalyst Laboratory of Subjectivity and Intersectionalities Production (LEPSI). Through the theory-practice-supervision tripod, this program offers extended psychosocial care to LGBT people in the context of deprivation of liberty in a prison unit located in the southern region of the state of Mato Grosso. These actions aim at minimizing psychosocial suffering from homo-lesbo-bi-transphobia, and by means of socio-educational actions, the empowerment of life, producing transformations in the institutional and egress life of the people on resocialization. We work in the schizoanalytic theoretical-methodological framework (cartographic method) and develop convergent and complementary actions, such as: individual psychological care; construction of community garden; reading club and remission project; wing self-management project; and socio-educational workshops and discussion groups on LGBT, Human Rights and Citizenship, employability, health, institutional and egress life that emerge in problematizations related to personal, social, programmatic and institutional vulnerabilities. We realize, therefore, that the program contributes to the strengthening of a space designed so that LGBT people in imprisonment situations can experience the institutionalized prison life and resocialization with the effects of reduced homo-lesbo-bitransphobia.
\end{abstract}

Keywords: Imprisonment; LGBT Population; Cartographic Method.

Recebido em: 03/01/2019

Aceito em: 29/01/2019

Vol. 01, N. 04, Out. - Dez., 2018 - www.revistas.unilab.edu.br/index.php/rebeh 